\title{
Development and Validation of a Simple and Efficient RPLC Method for Analysis of Captopril, Metformin, Pioglitazone and Glibenclamide in API, Formulations and Human Serum
}

\author{
Najma Sultana ${ }^{1}$, Safila Naveed ${ }^{1,2 *}$ and Saeed Arayne $\mathbf{M}^{3}$ \\ ${ }^{1}$ Department of Pharmaceutical Chemistry, Faculty of Pharmacy, University of Karachi, Karachi, Pakistan \\ ${ }^{2}$ Faculty of Pharmacy, Jinnah University for Women, Karachi, Pakistan \\ ${ }^{3}$ Department of Chemistry, University of Karachi, Karachi, Pakistan
}

\begin{abstract}
The association between the use of ACE inhibitors and the incidence of hypoglycemia is controversial. A recent study reported that $14 \%$ of all hospital admissions for hypoglycemia might be attributable to ACE inhibitors. In this paper, a novel, precise, specific, accurate and rapid reversed-phase high performance liquid chromatographic method was developed, optimized and validated for determining captopril and hypoglycemic (metformin, pioglitazone and glibenclamide) in bulk, pharmaceutical formulations and human serum with the best chromatographic peak resolution, reduced run time and low cost of analysis. The method was validated according to the US Food and Drug Administration (FDA) and ICH guidelines for the parameters: specificity, stability, limits of detection (LLOD), limits of quantification (LLOQ), linearity, accuracy, precision and recovery. This method showed the best resolution by using Hypersil ODS,C18 $(150 \times 4.6 \mathrm{~mm}, 5$ micron) column using mobile phase, methanol: water (70: $30 \mathrm{v} / \mathrm{v}$ ) adjusted to $\mathrm{pH} 3$ via ortho phosphoric acid $85 \%$ with flow rate of $1 \mathrm{mLmin}^{-1}$ at ambient temperature and wavelength of $230 \mathrm{~nm}$. The signal-to-noise ratio $(\mathrm{S} / \mathrm{N})$ was employed as a quality measurement. This tool permits to establish the influence of some selected factors (methanol: water ratio, $\mathrm{pH}$, and flow rate) on two responses (peak areas and retention time). The LLOD and LLOQ values for CAP, MET, PGL and GLB were found to be $2.3,1.5,2.3$ and 2.3 and $0.7,0.4,0.7$, and $0.7 \mu \mathrm{gmL}^{-1}$ respectively. Calibration curves were linear in the concentration range of $2.5-100 \mu \mathrm{gmL}^{-1}$ for hypoglycemic and captopril with regression coefficient $\left(r^{2}\right)$ value of 0.999 for all drugs. The data for accuracy, precision and recovery were within the FDA limits. Intra ad inter-day precision and accuracy results were 98.0 to $102 \%$. Retention time for captopril was found to be 3.3 minute and for metformin, pioglitazone and glibenclamide 2.4, 2.8, 7.2 minutes respectively. Proposed method was selective, precise and accurate short time analysis therefore can be used for routine, quality control and clinical study.

This is the first full report of a method for the simultaneous determination of these four drugs: captopril, metformin, pioglitazone and glibenclamide in API, formulations and serum. The newly developed method is useful for future routine analysis of these drugs and could be used in therapeutic drug monitoring and adherence to medicine studies, which would be helpful in decision making regarding treatment change in combination therapies.
\end{abstract}

Keywords: Captopril; Metformin; Glibenclamide; Pioglitazone; RPHPLC determination

\section{Introduction}

Captopril (Figure 1) is 1-[(2S)-3-mercapto-2-methyl-1-oxoproptonyl]-L-prolineis an orally active inhibitor of the angiotensinconverting enzyme and widely used for the treatment of hypertensive diseases on its own or in combination with other drugs [1]. ACEIs lower the blood pressure in hypertensive patients as well as in salt-depleted normotensive patients. ACE inhibitors are highly selective drugs, do not interact directly with other components of the rennin angiotensin system, and the principle pharmacological and clinical effects of ACE inhibitors seen to arise from suppression of synthesis of angiotensin II [2]. ACE inhibitors produce vasodilation by inhibiting the formation of angiotensin II. This vasoconstrictor is formed by the proteolytic action of renin (released by the kidneys) acting on circulating angiotensinogen to form angiotensin I which is then converted to angiotensin II by angiotensin converting enzyme. ACE inhibitors, by blocking the breakdown of bradykinin, increase its levels, which can contribute to the vasodilator action of ACE inhibitors.

Metformin hydrochloride (Figure 1) chemically, N, N dimethylimido dicarbonimidic diamide hydrochloride is an antidiabetic agent from biguanide class used in the management of type 2 diabetes. It decrease hepatic glucose production and intestinal absorption of glucose and improves insulin sensitivity by increasing peripheral glucose uptake and utilization, its predominant effect is to decrease fasting plasma glucose.

Pioglitazone hydrochloride (Figure 1) ( \pm )-5-[p-[2-(5-ethyl-2pyridyl)-ethoxy]benzyl]-2,4-thiazolidinedione hydrochloride is an oral antidiabetic agent used in the treatment of type 2 diabetes mellitus. PIO decreases insulin resistance in the periphery, liver and resulting in increased insulin-dependent glucose disposal and decreased hepatic glucose output.

Glibenclamide (Figure 1), 5-chloro-N-[2-4[[[(cyclohexylamino)

*Corresponding author: Safila Naveed, Faculty of Pharmacy, Jinnah University for Women, Karachi, Pakistan, E-mail: safila117@yahoo.com, safila117@gmail.com

Received June 11, 2013; Accepted July 15, 2013; Published July 19, 2013

Citation: Sultana N, Naveed S, Saeed Arayne M (2013) Development and Validation of a Simple and Efficient RPLC Method for Analysis of Captopril, Metformin, Pioglitazone and Glibenclamide in API, Formulations and Human Serum. Pharm Anal Acta 4: 257. doi:10.4172/2153-2435.1000257

Copyright: @ 2013 Sultana N, et al. This is an open-access article distributed unde the terms of the Creative Commons Attribution License, which permits unrestricted use, distribution, and reproduction in any medium, provided the original author and source are credited. 
Citation: Sultana N, Naveed S, Saeed Arayne M (2013) Development and Validation of a Simple and Efficient RPLC Method for Analysis of Captopril, Metformin, Pioglitazone and Glibenclamide in API, Formulations and Human Serum. Pharm Anal Acta 4: 257. doi:10.4172/21532435.1000257

Page 2 of 6<smiles>C[C@@H](CS)C(=O)N1CCCC1C(=O)O</smiles>

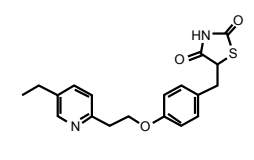

Captopril<smiles>CNC(=N)NC(=N)N</smiles>

Metformin

Figure 1: Structure of captopril and NIDDMs

carbonyl]-amino]sulphonyl]-henyl]ethyl]-2-methoxy benzamide is oral sulfonylurea antidiabetic agent widely used to lower blood glucose levels in patients with type 2 diabetes mellitus. It acts by inhibiting ATPsensitive potassium channels in pancreatic beta cells and this inhibition causes cell membrane depolarization, which cause voltage dependent calcium channels to open and increase in intracellular calcium in the beta cell, which stimulates insulin release.

For many patients with type 2 diabetes, mono therapy with an oral antidiabetic agent is not sufficient and the fixed dose combination of metformin, pioglitazone, and glibenclamide showed significant efficacy in improving the glycemic control in type 2 diabetics. Angiotensin converting enzyme inhibitors have been shown to be effective antihypertensive drugs for both patients with diabetes and those without diabetes. Diverse classes of antihypertensive prescription may be used for blood pressure manage in diabetes among these calcium channel blockers, thiazide diuretics and angiotensin converting enzyme inhibitors are common [3]. Various HPLC methods have been reported for estimation of captopril [4-6]. Several methods have also been developed for investigation of anti diabetics with other drugs [7-11]. Our research group has reported a number of methods for the simultaneous determination of these drugs as glipizide and glimepride [12] and now this method has been used for interaction studies. Metformin has been determined along with captopril, lisinopril and enalapril [13], gliquidone pioglitazone hydrochloride and verapamil has been simultaneously determined [14] and gliquidone, piogliquidone hydrochloride and atorvastatin in formulations and human serum [15]. We have also worked on the interaction of a number of co-administered drugs as interaction of captopril and $\mathrm{H}_{2}-$ receptor antagonists $[16,17]$.

Combinations of metformin with glipizide, gliclazide or glibenclamide are available commercially as single dosage form. A combination tablet formulation is beneficial in terms of its convenience and patient's compliance. The most important purpose of this study was to assess the "in vitro" drug interactions of captopril with commonly prescribed antidiabetic drugs (metformin, glibenclamide and pioglitazone) by utilizing HPLC for the monitoring of diabetic patients who take combination medications and for studying the pharmacokinetics of the combined dosage forms.

\section{Experimental}

\section{Materials and reagents}

All chemicals and reagents were of analytical grade. Captopril

(purity 99.82\%) was a kind gift from Bristol Meyers (Pvt) Limited, Pakistan. Metformin (purity 99.94\%), glibenclamide (purity 99.97\%) and pioglitazone (purity 99.79\%) were gifts from Sanofi Aventis (Pakistan) Ltd, Safe Pharmaceutical (Pvt) Ltd and Ali Gohar Pharmaceuticals (Pvt) Limited, Pakistan. HPLC grade acetonitrile, methanol and phosphoric acid were obtained from Tedia (USA) and Merck Darmstadt, Germany.

\section{Pharmaceutical dosage form}

Capoten $^{\text {Tx }}$ (Captopril $25 \mathrm{mg}$ tablets by Bristol Meyers (Pvt) Ltd), Neodipa $^{\text {tm }}$ (metformin $250 \mathrm{mg}$ tablets by Sanofi Aventis (Pvt) Ltd), Diazet $^{\text {tix }}$ Glibenclamide $5 \mathrm{mg}$ from Safe Pharmaceutical (Pvt) Ltd and Poze $^{\mathrm{mc}}$ (45 mg mg tablets from Ali Gohar pharmaceuticals Pakistan Limited), were purchased from the local pharmacies. All these drugs had an expiry of not less than 1 year at the time of study.

\section{Instrumentation}

A Shimadzu HPLC system equipped with LC- 10 AT VP pump and SPD-10 A VP UV-VIS detector and other HPLC system was equipped with LC-20AT and SPD-20A UV/VIS detector was utilized. Chromatographic system was integrated via Shimadzu model CBM102 to P-IV computer loaded with Shimadzu CLASS-VP software (Version 5.03) for data acquisition and mathematical calculations. Rheodyne manual injector fitted with a $20 \mu \mathrm{L}$ loop, Hypersil, ODS, C18 $\left(150 \times 4.6 \mathrm{~mm}, 5\right.$ micron) and Purospher ${ }^{\circledR}$ STAR RP-18 column and DGU-14 AM on-line degasser. In addition, Mattler Toledo electronic balance, micro liter syringe and micro pore filtration assembly were used in this study.

\section{Preparation of standard and sample solutions}

Standard preparation: Stock standard solutions 100 ppm of CAP, MET, PGL and GLB were prepared in $100 \mathrm{~mL}$ mobile phase as solvent. Working solutions were prepared separately by making serial dilutions from the standard solutions to obtain concentration between 2.5-100 $\mu \mathrm{g} \mathrm{mL}^{-1}$ for hypoglycemics and captopril. These solutions were stored at $20^{\circ} \mathrm{C}$. Once prepared, analyzed daily for inter and intra-day variations of the method. $20 \mu \mathrm{L}$ of these solutions were injected into LC system and chromatographed.

Preparation of solutions: Standard solutions of captopril and anti diabetic drugs were prepared by dissolving appropriate amounts of each in mobile phase methanol: water $(70: 30 \mathrm{v} / \mathrm{v}, \mathrm{pH} 3)$ to obtain final drug concentrations of $100 \mu \mathrm{g} \mathrm{mL}^{-1}$. For the calibration standards, seven calibrators of each drug were prepared by making serial dilutions from stock solutions. For the assay preparation the content of 20 tablets were powdered weighed portion of the powder equivalent to the suitable amount of drug (according to the labeled claimed) was transferred into a $50 \mathrm{~mL}$ volumetric flask. The drug was fully dissolved in mobile phase and then diluted with this solvent up to the mark, seven dilutions of each drug were prepared portion of this solution was filtered through a disposable $0.45 \mu \mathrm{m}$ filter and then injected.

Serum drug analysis: Blood samples were collected from healthy volunteers and after coagulation centrifuged at $3000 \mathrm{rpm}$ for 10 minutes. The supernatant (serum) obtained was stored at $-20^{\circ} \mathrm{C}$. After thawing, serum was deprotinated by acetonitrile and spiked daily with working solutions to produce desired concentrations of enalapril and anti diabetic drugs. $20 \mu \mathrm{L}$ volume of each sample was injected and chromatographed under above conditions.

Chromatographic conditions: The chromatographic analysis was performed at ambient temperature with isocratic elution. The mobile 
Citation: Sultana N, Naveed S, Saeed Arayne M (2013) Development and Validation of a Simple and Efficient RPLC Method for Analysis of Captopril, Metformin, Pioglitazone and Glibenclamide in API, Formulations and Human Serum. Pharm Anal Acta 4: 257. doi:10.4172/21532435.1000257

Page 3 of 6

phase consisted of methanol: water (70:30 v/v) with $\mathrm{pH}$ adjusted to 3 with phosphoric acid (85\%). The pump was set at a flow rate of $1.0 \mathrm{~mL}$ $\mathrm{min}^{-1}$, sample volume of $20 \mu \mathrm{L}$ was injected in triplicate onto the HPLC column and elute was monitored at $230 \mathrm{~nm}$. Optimal retention times for captopril, metformin, Pioglitazone and Glibenclamide was found to be $3.32 .4,2.8,7.2$ min respectively.

\section{Results and Discussion}

Development of HPLC methods for the determination of drugs has received considerable attention in recent years because of their importance in routine quality control analysis. HPLC methods generally require provision for use and disposal of solvents, laborintensive sample preparation procedure and personal skilled in chromatographic techniques. The goal of this study was to develop a rapid, more accurate, precise reliable least time consuming HPLC method for the simultaneous determination of captopril and anti diabetic drugs in the form of bulk drug samples, its formulations and human serum using the most commonly employed C-18 column with UV detector.

\section{Method development}

In the present investigation the best separation of captopril and antidiabetic drugs was achieved using a Hypersil, ODS, C18 (150×4.6 $\mathrm{mm}, 5$ micron) column which provides efficient and reproducible separation of the components. Using other type of column under similar experimental condition, the separation lasted about 8 minutes. A mobile phase of methanol: water $(70: 30 \mathrm{v} / \mathrm{v})$ having $\mathrm{pH}$ adjusted with phosphoric acid to 3 provided a reproducible, baseline resolved peak. Small changes in $\mathrm{pH}$ of the mobile phase had a great influence to the chromatographic behavior of these substances, higher $\mathrm{pH}$ of the mobile phase also results in peak tailing and at a lower $\mathrm{pH}$ retention time of antidiabetic drugs and captopril was delayed. It is obvious from the chromatogram (Figure 2 and 3 ) that antidiabetic drugs and captopril eluted out forming symmetrical peaks and were well separated from each other. The method was found to be rapid as the drugs separated in a very short time i.e. captopril $3.3 \mathrm{mins}$ and metformin, pioglitazone and glibenclamide 2.4, 2.8, 7.2 minutes respectively. The advantages of this method are ease of operation, short analysis time (total run time $<8$ minutes), utilization of readily available costeffective solvents, no matrix interferences and satisfactory limit of quantification to enable pharmacokinetic studies of captopril and hypoglycemic drugs. Rapidness, sensitivity, simplicity, economical nature, acceptable resolution, good recovery and precision of this method give it an advantage over the other reported HPLC methods for the determination of captopril and (non insulin dependent diabetes mellitus drugs) NIDDMs drugs.

\section{Method validation}

The newly developed method has been validated and holds well for the determination of drug in raw materials, dosage formulations and serum. For validation of analytical methods, the guidelines of the International Conference on the Harmonization of Technical Requirements for the Registration of Pharmaceuticals for Human Use [16] have recommended the accomplishment of selectivity, specificity, linearity, accuracy test, precision, sensitivity, limit of detection and quantification of the method.

\section{Selectivity and specificity}

The specificity of the chromatographic method was determined to ensure separation of captopril and antidiabetic as shown in Figure
3. Specificity was also determined by screening four different samples of controlled human serum, which were free from interfering endogenous plasma components. Solutions of placebo, captopril and antidiabetic were prepared and then injected to check for interference from common excepients (Table 1).

\section{Range and linearity}

Linearity is generally reported as the variance of the slope of the regression line. Linearity was tested with known concentrations of captopril, metformin, Pioglitazone and Glibenclamide i.e. 2.5, 5, 10, 25,

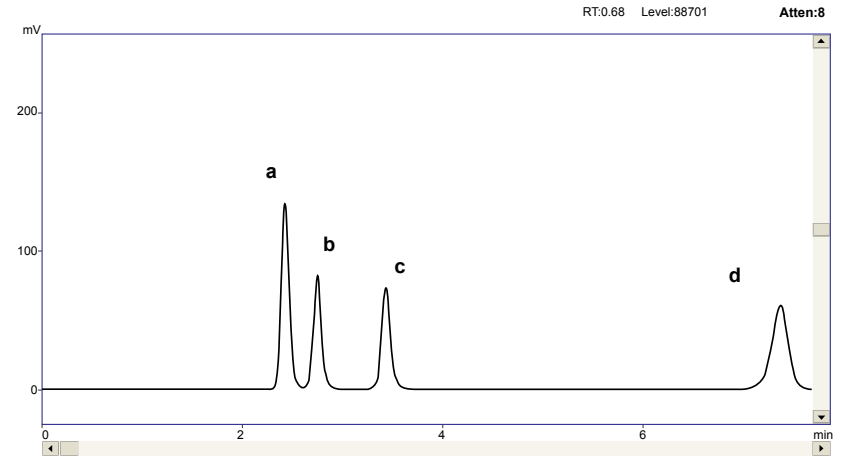

Figure 2: A representative chromatogram of (a) metformin (b) pioglitazone (c) captopril and (d) glibenclamide in API.

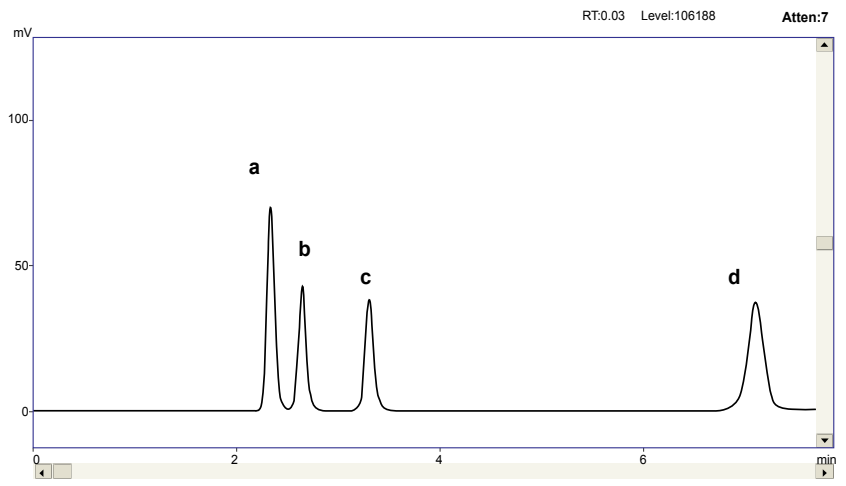

Figure 3: A representative chromatogram of (a) metformin (b) pioglitazone (c) captopril and (d) glibenclamide in formulation.

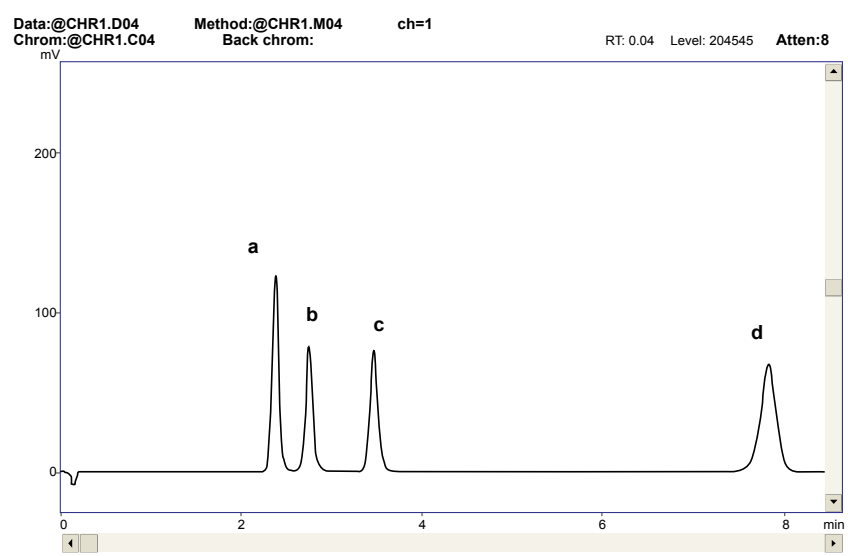

Figure 4: A representative chromatogram of (a) metformin (b) pioglitazone (c) captopril and (d) glibenclamide in serum. 
Citation: Sultana N, Naveed S, Saeed Arayne M (2013) Development and Validation of a Simple and Efficient RPLC Method for Analysis of Captopril, Metformin, Pioglitazone and Glibenclamide in API, Formulations and Human Serum. Pharm Anal Acta 4: 257. doi:10.4172/21532435.1000257

Page 4 of 6

50 and $100 \mu \mathrm{gmL}^{-1}$, respectively. Five runs were performed for every concentration. Injected concentrations versus area were plotted and the correlation coefficients were calculated which are shown in Table 2.

\section{Accuracy and recovery}

The accuracy of an analytical procedure measures the closeness of measured values to the true values. It was evaluated as percentage relative error between the measured mean concentrations and taken concentrations $[17,18]$. Minimal of three concentration levels covering the specified ranges were selected and three runs were performed for every concentration and then peak area was calculated as given in Table 3.

\section{Precision}

The intra-and inter-day precision was evaluated by assaying the samples (Table 4). In this assay, the intra-day precision and the interday precision recovery was $98-102 \%$ in bulk materials and in human serum (Figure 4). Intra and interday precision was performed and \% RSD was found to be less than 2 which indicate that the method was sufficiently accurate and precise.

\section{Robustness}

To evaluate robustness of the developed RP-HPLC method, small deliberate variations in the optimized method parameters were done. The effect of change in flow rate, $\mathrm{pH}$ and mobile phase ratio on the

\begin{tabular}{|c|c|c|c|c|c|c|}
\hline Analytes & $\begin{array}{l}\text { Retention } \\
\text { time }\left(T_{R}\right) \\
(\min )\end{array}$ & $\begin{array}{l}\text { Capacity } \\
\text { factors } \\
\text { (K') }\end{array}$ & $\begin{array}{l}\text { Theoretical } \\
\text { plates (N) }\end{array}$ & $\begin{array}{l}\text { Tailing } \\
\text { factor } \\
\text { (T) }\end{array}$ & $\begin{array}{l}\text { Resolution } \\
\text { (R) }\end{array}$ & $\begin{array}{l}\text { Separation } \\
\text { factor }\end{array}$ \\
\hline CAP & 3.3 & 2.13 & 3200 & 1.23 & 3.4 & 2.48 \\
\hline MET & 2.4 & 2.25 & 3250 & 1.25 & 3.5 & 2.36 \\
\hline PGL & 2.8 & 2.36 & 3250 & 1.36 & 3.6 & 2.59 \\
\hline GLB & 7.2 & 2.36 & 3246 & 1.69 & 3.3 & 2.56 \\
\hline
\end{tabular}

captopril (CAP), metformin (MET), Pioglitazone (PGL) and Glibenclamide (GLB)

Table 1: System suitability parameters.

\begin{tabular}{|l|l|l|l|l|l|}
\hline Drugs & Conc. $\boldsymbol{\mu g m L ^ { - 1 }}$ & $\begin{array}{l}\text { Regression } \\
\text { Equation }\end{array}$ & $\mathbf{r}^{2}$ & $\begin{array}{l}\text { LLOD } \\
\boldsymbol{\mu g m L ^ { - 1 }}\end{array}$ & LLOQ \\
\hline CAP & $2.5-100$ & $\mathrm{~A}=2501.7 \mathrm{x}+3073.7$ & 0.9995 & 0.7 & 2.3 \\
\hline MET & $2.5-100$ & $\mathrm{~A}=3841.3 \mathrm{x}+4744.2$ & 0.9998 & 0.4 & 1.5 \\
\hline PIO & $2.5-100$ & $\mathrm{~A}=2419.8 \mathrm{x}+2988.8$ & 0.9995 & 0.7 & 2.3 \\
\hline GLB & $2.5-100$ & $\mathrm{~A}=2419.8 \mathrm{x}+2988.8$ & 0.9995 & 0.7 & 2.3 \\
\hline
\end{tabular}

captopril (CAP), metformin (MET), Pioglitazone (PGL) and Glibenclamide (GLB)

Table 2: Regression characteristics.

\begin{tabular}{|c|c|c|c|c|c|}
\hline \multirow{2}{*}{ Analyte } & \multicolumn{3}{|c|}{ Assay (spiking method) } & \multicolumn{2}{|c|}{ Assay in serum } \\
\hline & Conc. ggmL $^{-1}$ & \%RSD & $\% \operatorname{Rec}$ & \%RSD & $\% \operatorname{Rec}$ \\
\hline \multirow{3}{*}{ CAP } & 8 & 0.01 & 99.98 & 0.002 & 102 \\
\hline & 10 & 0.33 & 100.04 & 0.02 & 101 \\
\hline & 12 & 0.36 & 99.97 & 0.03 & 101 \\
\hline \multirow{3}{*}{ MET } & 8 & 0.01 & 100 & 0.002 & 101 \\
\hline & 10 & 0 & 100.02 & 0.002 & 101.3 \\
\hline & 12 & 0.3 & 99.98 & 0.02 & 100.3 \\
\hline \multirow{3}{*}{ PGL } & 8 & 0.22 & 99.3 & 0.03 & 100.2 \\
\hline & 10 & 0.4 & 99.98 & 0.036 & 100.6 \\
\hline & 12 & 99.73 & 79.79 & 0.3 & 101.3 \\
\hline \multirow{3}{*}{ GLB } & 8 & 0.01 & 99.73 & 0.06 & 101.3 \\
\hline & 10 & 0.3 & 100.24 & 0.05 & 101.6 \\
\hline & 12 & 0.5 & 100.06 & 0.06 & 102.0 \\
\hline
\end{tabular}

Table 3: Accuracy of captopril and antidiabetic drugs.

\begin{tabular}{|c|c|c|c|c|c|}
\hline \multirow{2}{*}{ Drugs } & \multirow{2}{*}{$\begin{array}{l}\text { Conc. injected } \\
\mu \mathrm{gmL}^{-1}\end{array}$} & \multicolumn{2}{|c|}{ Inter-day } & \multicolumn{2}{|c|}{ Intra-day } \\
\hline & & \%RSD & $\% \operatorname{Rec}$ & $\%$ RSD & $\%$ Rec \\
\hline \multirow{6}{*}{ CAP } & 2.5 & 0.0073 & 101.11 & 0.073 & 101.11 \\
\hline & 5 & 0.0109 & 102.36 & 0.009 & 102.36 \\
\hline & 10 & 0.3261 & 100 & 0.361 & 100.02 \\
\hline & 25 & 0.0009 & 100 & 0.09 & 100.03 \\
\hline & 50 & 0.0005 & 99.826 & 0.005 & 99.26 \\
\hline & 100 & 0.0002 & 99.998 & 0.002 & 99.98 \\
\hline \multirow{6}{*}{ MET } & 1.25 & 0.0047 & 99.997 & 0.047 & 99.9 \\
\hline & 2.5 & 0.0071 & 99.988 & 0.071 & 99.88 \\
\hline & 5 & 0.0024 & 100.12 & 0.024 & 100.1 \\
\hline & 10 & 0.0006 & 99.983 & 0.006 & 99.93 \\
\hline & 25 & 0.0006 & 99.968 & 0.006 & 99.98 \\
\hline & 50 & 0.0003 & 99.991 & 0 & 99.91 \\
\hline \multirow{6}{*}{ PGL } & 1.25 & 0.0075 & 98.72 & 0.007 & 98.72 \\
\hline & 2.5 & 0.0075 & 99.98 & 0.075 & 99.98 \\
\hline & 5 & 0.0019 & 99.73 & 0.019 & 99.73 \\
\hline & 10 & 0.0012 & 99.97 & 0.012 & 99.87 \\
\hline & 25 & 0.0005 & 99.97 & 0.005 & 99.87 \\
\hline & 50 & 0.0003 & 100.02 & 0.003 & 100.1 \\
\hline \multirow{6}{*}{ GLB } & 1.25 & 0.008 & 100.02 & 0.08 & 100.2 \\
\hline & 2.5 & 0.008 & 99.783 & 0.008 & 99.7 \\
\hline & 5 & 0.002 & 99.983 & 0.002 & 99.9 \\
\hline & 10 & 0.001 & 99.972 & 0.001 & 99.9 \\
\hline & 25 & 0.05 & 99.996 & 0.05 & 99.9 \\
\hline & 50 & 0.03 & 99.997 & 0.03 & 99.9 \\
\hline
\end{tabular}

Table 4: Inter day and intraday precision of captopril and NIDDM drugs.

\begin{tabular}{|c|c|c|c|c|}
\hline & Level & $K^{\prime}$ & $\mathbf{T}$ & $\left(\mathbf{R}_{\mathrm{s}}\right)$ \\
\hline \multicolumn{5}{|c|}{ A: pH of mobile phase } \\
\hline 2.6 & -0.2 & 2.8 & 1.22 & 3.4 \\
\hline 2.8 & 0 & 2.13 & 1.23 & 3.4 \\
\hline 3 & 0.2 & 2.2 & 1.4 & 3.2 \\
\hline \multicolumn{2}{|c|}{ Mean \pm S.D $(n=6)$} & $2.13 \pm 0.3$ & $1.23 \pm 0.020$ & $3.4 \pm 0.1$ \\
\hline \multicolumn{5}{|c|}{ B: Flow rate $\left(\mathrm{mLmin}^{-1}\right)$} \\
\hline 0.8 & -0.2 & 2.1 & 1.45 & 3.32 \\
\hline 1 & 0 & 2.3 & 1.44 & 3.36 \\
\hline 1.2 & 0.2 & 2.4 & 1.42 & 3.37 \\
\hline \multicolumn{2}{|c|}{ Mean \pm S.D $(n=6)$} & $4.3 \pm 0.212$ & $1.44 \pm 0.015$ & $3.36 \pm 0.026$ \\
\hline \multicolumn{5}{|c|}{ C: Percentage of water in mobile phase (V/V) } \\
\hline 25 & -5 & 2.6 & 1.42 & 3.38 \\
\hline 30 & 0 & 2.3 & 1.43 & 3.36 \\
\hline 35 & 5 & 2.5 & 1.46 & 3.33 \\
\hline \multicolumn{2}{|c|}{ Mean \pm S.D $(n=6)$} & $2.36 \pm 0.070$ & $1.43 \pm 0.025$ & $3.36 \pm 0.025$ \\
\hline \multicolumn{5}{|c|}{ C: Wavelength $(\mathrm{nm})$} \\
\hline 225 & -5 & 2.5 & 1.42 & 3.38 \\
\hline 230 & 0 & 2.3 & 1.43 & 3.36 \\
\hline 235 & 5 & 2.4 & 1.45 & 3.32 \\
\hline \multicolumn{2}{|c|}{ Mean \pm S.D $(n=6)$} & $2.3 \pm 0.070$ & $1.43 \pm 0.015$ & $2.36 \pm 0.030$ \\
\hline
\end{tabular}

Table 5: Robustness of the method $(n=6)$.

retention time and tailing factor were studied. The method was found to be unaffected by small changes like \pm 0.2 change in $\mathrm{pH}, \pm 0.2$ change in flow rate and \pm 5 change in mobile phase (Table 5 ).

\section{Ruggedness}

Ruggedness was established by determining CAP, MET, PGL and GLB using same and different chromatographic systems and using two different columns Hypersil, ODS, C18 $(150 \times 4.6 \mathrm{~mm}, 5 \mathrm{micron})$ and Purospher ${ }^{\circledR}$ STAR RP-18 column and Hypersil, ODS, gave the best 
Citation: Sultana N, Naveed S, Saeed Arayne M (2013) Development and Validation of a Simple and Efficient RPLC Method for Analysis of Captopril, Metformin, Pioglitazone and Glibenclamide in API, Formulations and Human Serum. Pharm Anal Acta 4: 257. doi:10.4172/21532435.1000257

Page 5 of 6

\begin{tabular}{|c|c|c|c|c|c|c|}
\hline \multicolumn{2}{|c|}{ HPLC System-----> } & \multirow[b]{2}{*}{ Conc. $\left(\mu \mathrm{gmL}^{-1}\right)$} & \multicolumn{2}{|c|}{ LC 10} & \multicolumn{2}{|c|}{ LC 20} \\
\hline Drugs & Columns & & Conc.Found $\left(\mu \mathrm{gmL}^{-1}\right)$ & Recovery (\%) & Conc. Found $\left(\mu \mathrm{gmL}^{-1}\right)$ & Recovery (\%) \\
\hline \multirow[b]{6}{*}{ CAP } & \multirow[b]{3}{*}{ Purospher STAR } & 30 & 30.03 & 100.1 & 30.03 & 100.1 \\
\hline & & 40 & 40.9 & 102.25 & 40.03 & 100.07 \\
\hline & & 50 & 50 & 100.0 & 50 & 100.0 \\
\hline & \multirow[b]{3}{*}{ Hypersil,ODS } & 30 & 30.09 & 100.3 & 30.04 & 100.13 \\
\hline & & 40 & 40 & 100.0 & 40 & 100.0 \\
\hline & & 50 & 50.03 & 100.06 & 50.03 & 100.06 \\
\hline \multirow[b]{6}{*}{ MET } & \multirow[b]{3}{*}{ Purospher STAR } & 30 & 30.09 & 100.3 & 30.04 & 100.13 \\
\hline & & 40 & 40 & 100.0 & 40 & 100.0 \\
\hline & & 50 & 50.02 & 100.04 & 50.02 & 100.04 \\
\hline & \multirow[b]{3}{*}{ Hypersil,ODS } & 30 & 30.04 & 100.133 & 30.04 & 100.13 \\
\hline & & 40 & 40.33 & 100.825 & 40.34 & 100.85 \\
\hline & & 50 & 50.23 & 100.46 & 50.23 & 100.46 \\
\hline \multirow[b]{6}{*}{ PGL } & \multirow[b]{3}{*}{ Purospher STAR } & 30 & 30.22 & 100.73 & 30.22 & 100.73 \\
\hline & & 40 & 40.02 & 100.05 & 40.02 & 100.05 \\
\hline & & 50 & 50.09 & 100.18 & 50.09 & 100.18 \\
\hline & \multirow[b]{3}{*}{ Hypersil,ODS } & 30 & 30.3 & 101.0 & 30.3 & 101.0 \\
\hline & & 40 & 40.09 & 100.22 & 40.09 & 100.22 \\
\hline & & 50 & 50.09 & 100.18 & 50.19 & 100.38 \\
\hline \multirow[b]{6}{*}{ GLB } & \multirow[b]{3}{*}{ Purospher STAR } & 30 & 30.04 & 100.13 & 30.04 & 100.13 \\
\hline & & 40 & 40.09 & 100.22 & 40.09 & 100.22 \\
\hline & & 50 & 50.09 & 100.18 & 50.09 & 100.18 \\
\hline & \multirow[b]{3}{*}{ Hypersil,ODS } & 30 & 30.09 & 100.3 & 30.06 & 100.20 \\
\hline & & 40 & 40.03 & 100.07 & 40.03 & 100.07 \\
\hline & & 50 & 50.06 & 100.12 & 50.06 & 100.12 \\
\hline
\end{tabular}

Table 6: Ruggedness of the method.

results. The assay results indicated that the method was capable with high precision (Table 6).

\section{Lower limit of detection and quantification}

The lower limit of quantitation (LLOQ) of the method as signal/ noise of captopril, metformin, Pioglitazone and Glibenclamide were found to be $2.3,1.5,2.3$ and $2.3 \mu \mathrm{gmL}^{-1}$ respectively. Similarly a signal/noise of 3, a LLOD of captopril, metformin, Pioglitazone and Glibenclamide were determined to be $0.7,0.4,0.7$, and $0.7 \mu \mathrm{gmL}^{-1}$ respectively.

\section{Conclusion}

The novel RP-HPLC method described in this paper provides a simple, universal, short time analysis and reproducible approach for the simultaneous identification and quantification that can be used to determine captopril and any of the three NIDDMs. In summary, the proposed method can be used for drug analysis in routine quality control. In addition, this method has the potential application to clinical research of drug combination, multi-drug pharmacokinetics and drug-drug interactions.

\section{References}

1. Wilson CO, Gisvold O, Jaime ND, William AR (1991) Wilson and Gisvold's Text Book of Organic Medicinal and Pharmaceutical Chemistry. (9thedn) JB Lippincott Company, USA: 564.

2. Myceh MJ (2000) Lippincott's Illustrated Reviews Pharmacology, (2ndedn), Lippincott William \& Wilkins.

3. Curtis T (2006) Drug interactions of medications commonly used in diabetes. Diabetes Spectrum 19: 202-211.

4. Sultana N, Arayne MS, Naveed S (2010) Simultaneous Determination of Captopril and Statins in active pharmaceutical ingredients, Pharmaceutical Formulations and in Human Serum by RP-HPLC. J Chin Chem Soc 57: 378383
5. Sultana N, Arayne MS, Naveed S (2010) Simultaneous Quantitation of Captopril and NSAIDs in API, Dosage Formulations and Human Serum by RPHPLC. Journal of the Chinese Chemical Society 57: 62-67.

6. Sultana N, Arayne MS, Naveed S (2011) RP-HPLC method for simultaneous determination of captopril and diuretics: application in pharmaceutical dosage forms and human serum. Chromatography Separation Sciences. $2: 4$

7. Jain D, Jain S, Jain D, Amin M (2008) Simultaneous estimation of metformin hydrochloride, pioglitazone hydrochloride, and glimepiride by RP-HPLC in tablet formulation. J Chromatogr Sci 46: 501-504.

8. A K, G S, C MR, Bhat K, A R, et al. (2008) Simultaneous determination of pioglitazone and glimepiride in bulk drug and pharmaceutical dosage form by RP-HPLC method. Pak J Pharm Sci 21: 421-425.

9. Venkatesh P, Harisudhan T, Choudhury H, Mullangi R, Srinivas NR (2006) Simultaneous estimation of six anti-diabetic drugs--glibenclamide, gliclazide, glipizide, pioglitazone, repaglinide and rosiglitazone: development of a nove HPLC method for use in the analysis of pharmaceutical formulations and its application to human plasma assay Biomed Chromatogr 20: 1043-1048.

10. Al-Arfaj NA, Al-Abdulkareem EA, Aly FA (2008) A Validated Adsorptive Stripping Voltammetric Determination of Antidiabetic Agent Pioglitazone $\mathrm{HCl}$ in Tablets and Biological Fluids. Int J Biomed Sci 4: 310-318.

11. Lakshmi KS, Rajesh T (2011) Separation and quantification of eight antidiabetic drugs on a high-performance liquid chromatography: its application to human plasma assay. ISRN Pharm 2011: 521353.

12. Sultana N, Arayne MS, Ali SN, Zuberi MH (2012) Simultaneous determination of glipizide and glimepride by RP-HPLC in dosage formulations and in human serum. Medicinal Chemistry Research 21: 2443-2448.

13. Arayne MS, Zuberi MH, Siddiqui FA (2012) Simultaneous RP-HPLC method fo the determination of metformin captopril, lisinopril and enalapril: Its applications in dosage formulations and in human plasma. Medicinal Chemistry Research 21: $4542-4548$.

14. Arayne MS, Sultana N, Mirza AZ (2011) Simultaneous determination of gliquidone, pioglitazone hydrochloride, and verapamil in formulation and human serum by RP-HPLC. J Chromatogr Sci 49: 114-117.

15. Mirza AZ, Arayne MS, Sultana N (2013) RP-LC method for the simultaneous determination of gliquidone, pioglitazone hydrochloride, and atorvastatin in formulations and human serum. J AOAC Int 96: 56-59. 
Citation: Sultana N, Naveed S, Saeed Arayne M (2013) Development and Validation of a Simple and Efficient RPLC Method for Analysis of Captopril, Metformin, Pioglitazone and Glibenclamide in API, Formulations and Human Serum. Pharm Anal Acta 4: 257. doi:10.4172/21532435.1000257

16. Sultana N, Naveed S, Arayne MS (2013) RP-HPLC method for simultaneous determination of captopril and $\mathrm{H} 2$-receptor antagonist: Application to interaction studies Med Chem3: 183-187.

17. International Conference on Hormonisation of Technical Requirements for Registration of Pharmaceuticals for Human Use, $\mathrm{ICH}$ Harmonised Tripartite Guideline; Validation of Analytical Procedures: Text and Methodology Q2(R
1), Complementary Guideline on Methodology dated 06 November 1996, incorporated in November 2005, London

18. Shabir GA (2003) Validation of high-performance liquid chromatography methods for pharmaceutical analysis. Understanding the differences and similarities between validation requirements of the US Food and Drug Administration, the US Pharmacopeia and the International Conference on Harmonization. J Chromatogr A 987: 57-66. 